Submission ID: 43851

\title{
Integrated Technology of Planning and Geological Support of Well Drilling
}

M.V. Ovcharenko* (Roxar Services AS), A.N. Lanin (Roxar Services AS), I.V. Evdokimov (Roxar Services AS)

\section{SUMMARY}

Well planning, support of well drilling, geological modeling, hydrodynamic modeling 


\section{Комплексная технология планирования и геологического сопровождения бурения скважин}

М.В. Овчаренко* (ООО «Роксар Сервисиз»), А.Н. Ланин (ООО «Роксар Сервисиз»), И.В. Евдокимов (ООО «Роксар Сервисиз»)

\section{Введение}

В последние десятилетия отмечается неуклонный рост фонда скважин с горизонтальным окончанием. При строительстве высокотехнологичных скважин возрастают капитальные вложения и цена ошибки при бурении и заканчивании.

Эффективность проводки горизонтальных скважин по коллекторам остается одним из ключевых показателей технологической эффективности влияющим на пусковые и накопленные показатели скважины по нефти, несмотря на то, что большинство скважин с горизонтальным окончанием вводится в эксплуатацию с МГРП, поскольку эффект от МГРП снижается и/или исчезает через 0.5-3 года эксплуатации, а технология повторных МГРП в ГС пока не нашла широкого внедрения.

\section{Комплексная технология}

Применение комплексной технологии планирования и геологического сопровождения бурения скважин (Рисунок 1) подразумевает создание ПДГТМ, с использованием всех имеющихся геолого-геофизических, промысловых и исторических данных, находящейся в непрерывном мониторинге.

Геологическое сопровождение бурения возможно посредством простых методов, например путем построения разреза и траектории в табличном редакторе, в 2Д симуляторе путем выбора с использованием одной из нескольких опорных скважин и совмещению реальных и синтетических кривых. Данные подходы не позволяют использовать весь набор исходных геолого-геофизических данных и результатов их обработки, учесть и минимизировать неопределенности и риски при планировании и сопровождении бурения горизонтальных скважин.

Основные неопределенности и риски при планировании и сопровождении:

- Структурные (погрешность инклинометрии и результатов интерпретации сейсмических данных).

- Параметрические (эффективные толщины, ФЕС, текущие параметры пласта - насыщение, давление).

- Технологические (прихваты, поглощения, проявления, недоход нагрузок и пр.).

Технология условно разделяется на 4 этапа. На первом этапе вырабатывается первоначальная или корректируется уже существующая стратегия бурения, определяющая очередность и местоположение всех горизонтальных и наклонно-направленных скважин, вырабатывается дерево решений, рассчитываются запускные и накопленные показатели каждой скважины. До начала бурения первой и последующих скважин выдаются цели и геологический проект на бурение.

На втором этапе осуществляется геологическое сопровождение бурения (в случае бурения горизонтальной скважины), который можно разделить на два отрезка: сопровождение до точки T1 и сопровождение горизонтального участка скважины от точки Т1 до забоя. При бурении до точки Т1 записывается только каротаж необходимый для привязки транспортного ствола(для ГС) и корректировок профиля (для БГС), в ходе сопровождения бурения горизонтального участка используются следующие данные: инклинометрия, каротаж (естественная радиоактивность пород, удельные электрические сопротивления), описание шлама, люминисцентно-битуминозный анализ вытяжек, соотношение газовых фракций. Так же большое значение имеют результаты интерпретации сейсмических данных используемые при построении создании и мониторинге ПДГТМ, т.к. они являются основой структурной модели, 
с помощью которой прогнозируется поведение целевого пласта в азимуте бурения. Особенно это актуально в зонах осложненных тектоническими нарушениями и неразбуренных зонах.

Корректировка структурной модели во время сопровождения бурения осуществляется с помощью фиктивных вертикальных скважин, которые позволяют явно задать текущее положение ствола в пласте согласно показаниям ГК, их соответствию синтетически рассчитанным по опорным скважинам и текущему представлению на основе всех имеющихся данных.

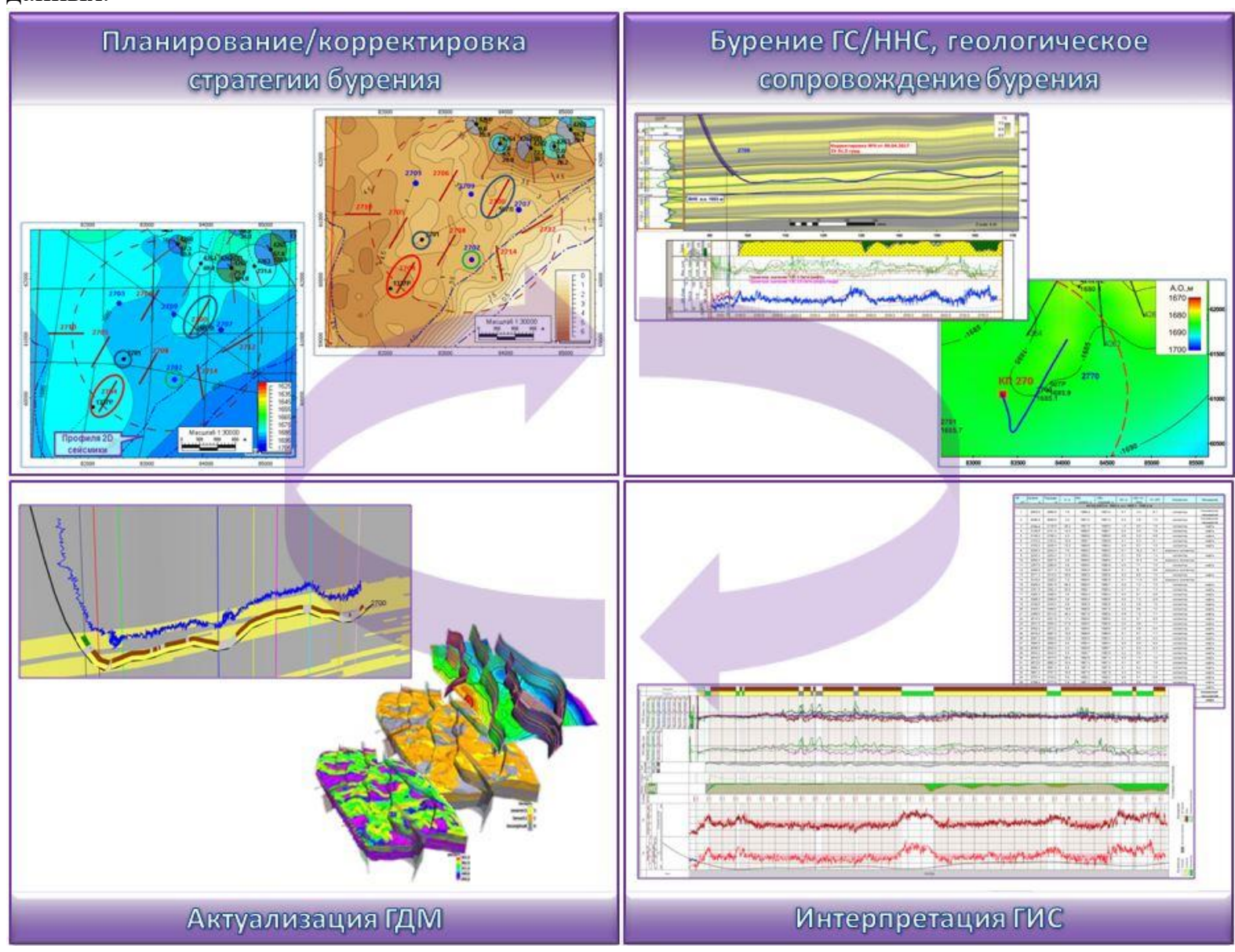

Рисунок 1 Обобщенная схема этапов комплексной технологии планирования и геологического сопровождения бурения скважин на примере кустовой площадки

Метод гамма каротажа (ГК), выбран как наилучшим образом расчленяющий разрез. В качестве опорных для расчета синтетического каротажа, выбираются ближайшие наклоннонаправленные скважины. Синтетический каротаж ГК создается из каротажа ГК окружающих скважин, путем переноса данных с опорных скважин и осреднения их на горизонтальный участок ствола бурящейся скважины. Значение синтетического каротажа рассчитанного из скважин окружения, переносится согласно структурной модели на горизонтальный участок ствола "подсаживаемой” скважины. Значения, полученные из нескольких опорных скважин, усредняется и взвешиваются на расстояние от ГС до опорных скважин. Если синтетический каротаж не совпадает с фактическим, то в этих участках структурная модель корректируется с помощью фиктивных скважин. После перестроения, синтетический каротаж пересчитывается с учетом обновленной структуры. При корректировке структурной модели необходимо контролировать результат перестроения на разрезе, чтобы не допустить “негеологичность" структурной модели (углы падения структуры). Стоит отметить, что процесс геологического сопровождения является непрерывным и требует круглосуточного контроля.

Третий этап - интерпретация данных полученных во время бурения или окончательного каротажа в открытом стволе, как правило включающего в себя модули ГК+2ННКт, ВИКИЗ+ПС, ГГКп. В процессе бурения так же производится оперативная интерпретация с использованием всех полученных данных. 


\section{EAGE}

Четвертый этап - учет горизонтального пробуренного ствола скважины в ПДГТМ. По результатам бурения корректируется структурная модель, обновляются параметры ГМ (литология, Кп, Кпр, Кнг), обновляется ГДМ, актуализируются запускные параметры по всем скважинам кустовой площадки. Оценкой качества является соответствие проектных и фактических запускных параметров скважины. В дальнейшем корректируется стратегия дальнейшего бурения.

\section{Пример №1}

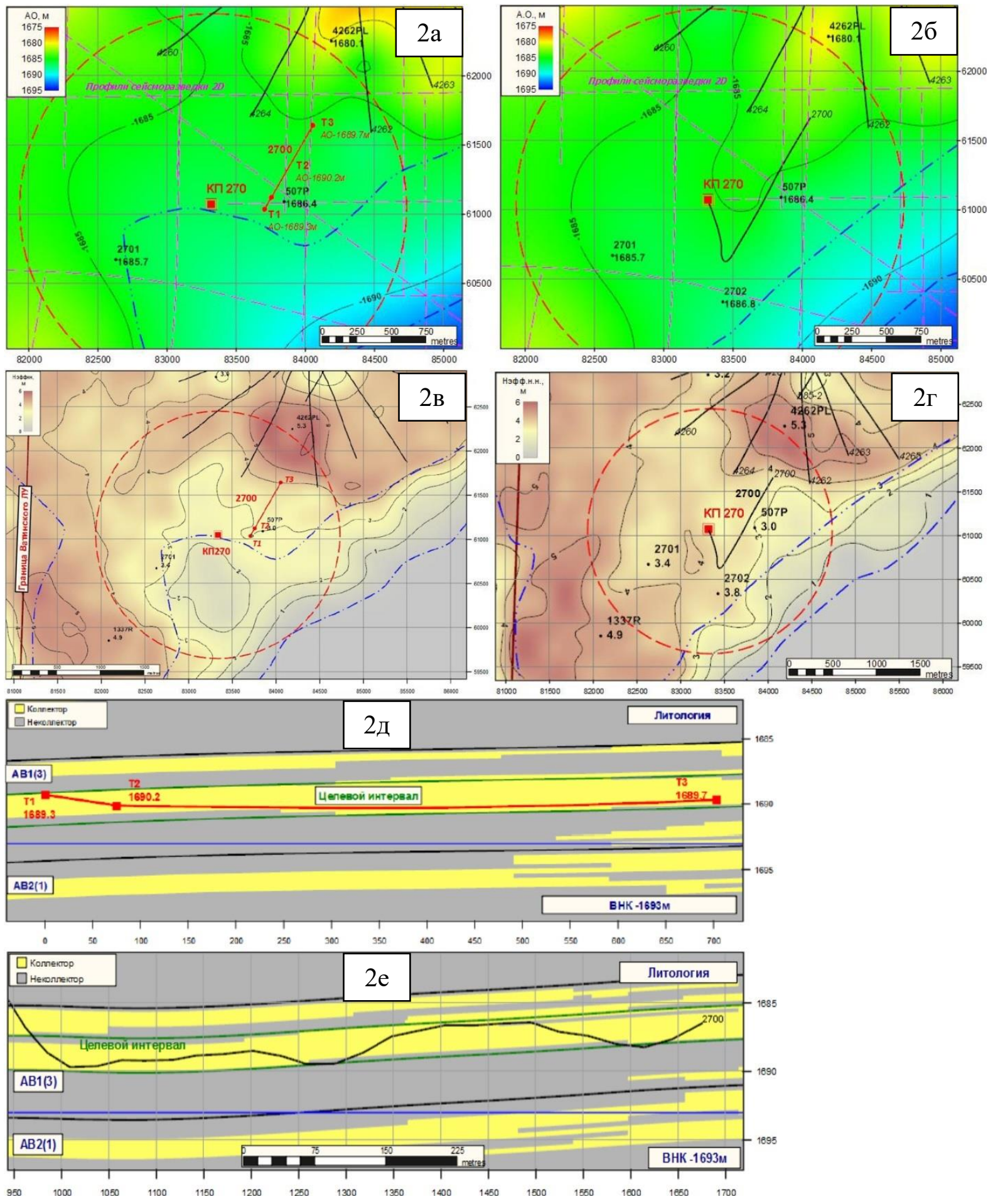

Рисунок 2 а) структурная карта до бурения ГС 2700 и ННС 2702; б) структурная карта после бурения; в) карта эффективных нефтенасыщенных толщин до бурения; г) карта 
эффективных нефтенасыщенных толщин после бурения; 2d) разрез вдоль проектной траектории скв. 2700 по литологии до бурения; 2е) разрез вдоль пробуренной траектории скв. 2700.

До начала бурения горизонтальной скважины 2700 (Рисунок 2) предполагалось более пологое залегание структуры, ниже по абсолютным отметкам. В процессе привязки транспортного ствола прогноз на кровлю пласта был скорректирован согласно данным ГИС бурящейся скважины, что позволило корректно посадить транспортный ствол. Эффективность проводки горизонтальной части данного ствола составляет $81 \%$ от общей длины при запланированных $75 \%$, так же успешно была выполнена задача уточнения структурного плана (отбита подошва целевого интервала пласта).

Согласно оценке пусковые показатели данной скважины составляли Qж=101.5 м3/сут, Qн=47.4 т/сут, обв. $=45.7 \%$, при Рзаб=130 атм., фактические показатели составили Qж=116.3 м3/сут, $\mathrm{QH}=50.1$ т/сут, обв. $=50 \%$, при Рзаб=122.9 атм.

\section{Выводы}

Ежегодно с использование данной технологии планируется и реализуется порядка 100 горизонтальных скважин, сходимость запускных параметров составляет более $85 \%$, при условии отклонения до $\pm 25 \%$ от запланированных. Использование данной технологии позволило повысить эффективность проводки скважин в среднем по предприятию до $87 \%$ на текущий момент, до начала работ эффективность составляла $64 \%$.

\section{Список литературы}

1. А.А. Молчанов, Э.Е. Лукьянов, В.А. Рапин. Геофизические исследования горизонтальных нефтегазовых скважин: учебное пособие. - С.-Петербург: Международная академия наук экологии, безопасности человека и природы (МАНЭБ), 2001, 298 с.

2. Кульчицкий В.В. Геонавтика - непременное условие развития нефтегазовых технологий будущего. // Технологии нефти и газа. -2005.- №5-6- С. 74-80.

\section{References}

1. A.A. Molchanov, E.Ye. Luk'yanov, V.A. Rapin. Geofizicheskiye issledovaniya gorizontal'nykh neftegazovykh skvazhin: uchebnoye posobiye. - S.-Peterburg: Mezhdunarodnaya akademiya nauk ekologii, bezopasnosti cheloveka i prirody (MANEB), 2001, $298 \mathrm{~s}$.

2. Kul'chitskiy V.V. Geonavtika - nepremennoye usloviye razvitiya neftegazovykh tekhnologiy budushchego. // Tekhnologii nefti i gaza. -2005.- №5-6- S. 74-80. 